\title{
A percepção de casais no período gestacional sobre violência obstétrica
}

The perception of couples during pregnancy about obstetric violence

La percepción de las parejas durante el embarazo sobre la violencia obstétrica

Amanda de Moura Borba袜, Ana Paula Pereira da Silva ${ }^{1}$, Juliana Clis Carneiro da Silva ${ }^{1}$, Júlio César Bernardino da Silva ${ }^{1}$, Nayale Lucinda de Andrade Albuquerque ${ }^{1}$, Vanessa Juvino de Sousa ${ }^{1}$.

\section{RESUMO}

Objetivo: Descrever a percepção de casais no período gestacional sobre violência obstétrica. Métodos: Trata-se de um estudo qualitativo, descritivo e exploratório, realizado com 8 casais de uma Unidade de Saúde da Família que participaram de uma entrevista a partir de um instrumento semiestruturado elaborado pelos autores. Analisaram-se os dados pela técnica de análise de conteúdo temático e os resultados foram apresentados a partir de categorias. O estudo foi aprovado por Comitê de Ética em Pesquisa. Resultados: Evidenciou-se que os casais consideraram a violência obstétrica como o mal atendimento dos profissionais de saúde durante o parto, não sendo citados momentos de pré-natal e puerpério. A violência obstétrica foi descrita como a postura dos profissionais, ao se expressarem de forma grosseira ou ao ignorar ou desvalorizar o casal, dessa forma violando o direito da mulher de ser tratada com respeito e dignidade. Conclusão: Sinaliza-se para a continuidade das discussões sobre a violência obstétrica como tema que necessita ser discutido, a partir de seu conceito, características, consequências e momentos de ocorrência. Essas discussões devem ser alvo frequentes na formação popular, na formação e educação permanente dos profissionais de saúde.

Palavras-chave: Enfermagem, Violência, Obstetrícia, Gestantes.

\begin{abstract}
Objective: The describe the perception of couples during pregnancy about obstetric violence. Methods: This is a qualitative, descriptive and exploratory study conducted with 8 couples from a Family Health Unit who participated in an interview using a semi-structured instrument. The data analysis occurred using thematic analysis technique and the results were presented from categories. The study was approved by the Research Ethics Committee. Results: It was evidenced that couples considered obstetric violence as the poor care of health professionals during childbirth, not mentioning prenatal and postpartum moments. Obstetric violence was described as the attitude of professionals, when expressing themselves rudely or ignoring or devaluing the couple, thus violating the woman's right to be treated with respect and dignity. Conclusion: It points to the continuity of discussions about obstetric violence as a theme that needs to be discussed, from its concept, characteristics, consequences and moments of occurrence. These discussions should be frequent targets in popular education, training and continuing education of health professionals.
\end{abstract}

Key words: Nursing, Violence, Obstetrics, Pregnant.

\section{RESUMEN}

Objetivo: Describir la percepción de las parejas durante el embarazo sobre la violencia obstétrica. Métodos: Este es un estudio cualitativo, descriptivo y exploratorio realizado con 8 parejas de una Unidad de Salud Familiar que participaron en una entrevista utilizando un instrumento semiestructurado preparado por los

${ }^{1}$ Centro Universitário Tabosa de Almeida (ASCES-UNITA), Caruaru - PE.

*E-mail: amandaaborba74@gmail.com 
autores. Los datos se analizaron mediante una técnica de análisis de contenido temático y los resultados se presentaron por categorías. El estudio fue aprobado por el Comité de Ética en Investigación. Resultados: Se evidenció que las parejas consideraban la violencia obstétrica como el mal cuidado de los profesionales de la salud durante el parto, sin mencionar los momentos prenatales y posparto. La violencia obstétrica se describió como la actitud de los profesionales, al expresarse groseramente o ignorar o devaluar a la pareja, violando así el derecho de la mujer a ser tratada con respeto y dignidad. Conclusión: Señalase la continuidad de las discusiones sobre la violencia obstétrica como un tema que necesita ser discutido, desde su concepto, características, consecuencias y momentos de ocurrencia. Estas discusiones deben ser objetivos frecuentes en educación popular, capacitación y educación continua de los profesionales de la salud.

Palabras clave: Enfermería, Violencia, Obstetricia, Embarazo.

\section{INTRODUÇÃO}

O parto normal é definido como uma prática repleta de significados, a partir da cultura da parturiente, sendo caracterizado como uma situação transformadora na vida da mulher. Percebe-se que, nos primeiros tempos, os partos eram realizados no próprio domicílio por pessoas de extrema confiança da família, as quais detinham um conhecimento sobre a realização do cuidado no parto, chamadas de parteiras ou aparadeiras e, nesse ambiente familiar, a mulher expressava livremente seus sentimentos e medos (SANFELICE CF, et al., 2014).

Observou-se, no decorrer da história e com o avanço da medicina, a adoção de uma prática da realização dos partos por parte dos profissionais, tornando-o um evento hospitalocêntrico e envolvido por intensa medicalização. Com isso, passaram a ocorrer deficiência de atenção às necessidades da parturiente e a forma mecanizada de tratá-las, afetando o emocional, físico e moral das mulheres, atualmente sendo caracterizadas como violência obstétrica (SANFELICE CF, et al., 2014).

A expressão violência obstétrica é utilizada para "descrever e agrupar diversas formas de violência ou danos ocasionados durante os cuidados dos profissionais, incluindo maus tratos físicos, psicológicos e verbais, assim como procedimentos desnecessários e danosos" (TESSER CD, et al., 2015).

Considera-se ainda, a violência obstétrica está relacionada à gestante e a sua família durante o pré-natal, parto e puerpério ou em situações de abortamento. Caracterizando-se por impedir a presença contínua do acompanhante da gestante independente do sexo, falta de informações ou autorização sobre procedimentos, não oferecer opções para alívio da dor, impedir que a mulher escolha a posição no parto, proibir a ingestão de líquidos ou alimentos leves durante o trabalho de parto, sucessivos toques vaginais sem indicação, ironizar ou não deixar que a mulher tenha liberdade de expressão, impedir o contato pele a pele na $1^{\circ}$ hora de vida assim como qualquer conduta que prejudique assistência à gestante/parturiente/puérpera/ recém-nascido assim como danifique seus direitos (BRASIL, 2015).

Como exemplos de violência obstétrica, cita-se o uso de medicações para acelerar o trabalho de parto, utilizando-se de hormônios sintéticos; a realização de força sobre a barriga da mulher em trabalho de parto, com o intuito de empurrar o bebê, chamada de manobra de Kristeller; o uso costumeiro de lavagem entérica, com o intuito de esvaziar o intestino para evitar a presença de fezes no momento do parto; a retirada dos pelos da região pubiana, conhecido como tricotomia; o exame de toque sucessivo para verificar a dilatação cervical (ALVARENGA SP e KALI JH, 2014).

Percebeu-se, no contato com o tema na graduação, um certo desconhecimento das situações que são caracterizadas como tal violência obstétrica entre os estudantes, entre os profissionais de saúde e entre as pessoas que buscam os serviços de saúde.

Estimulou-se, assim, a investigação do tema e a leitura de artigos e documentos, sendo também percebido que são escassas as publicações sobre o tema em Pernambuco e, consequentemente, no município de Caruaru. Dessa forma, o objetivo do presente estudo foi descrever a percepção de casais no período gestacional sobre violência obstétrica. 


\section{MÉTODOS}

Estudo de abordagem qualitativa, do tipo descritivo e exploratório, realizada em um município do estado pernambucano, entre os meses de dezembro de 2018 a abril de 2019. Entrevistou-se 9 casais (18 participantes), correspondentes à área adscrita da unidade, considerando-se a perda de um casal por desistência durante a entrevista. Desta forma, um total de 8 casais grávidos (16 entrevistados) participaram da pesquisa, o qual utilizou-se o método de saturação das entrevistas, quando as respostas dos casais grávidos começaram a coincidir.

Foram incluídos os casais grávidos heterossexuais ou homossexuais que estavam vivenciando pela primeira vez a gestação, bem como os que já vivenciaram gestações anteriores. Excluíram-se as gestantes que não possuíam companheiro, adolescentes e gestantes com problemas mentais. A coleta de dados foi realizada no período de dezembro de 2018 a abril de 2019, mediante uma entrevista semiestruturada.

O roteiro de entrevista utilizado na pesquisa foi elaborado e validado pelos próprios pesquisadores com questões referentes à caracterização sociodemográfica e também, constituído por perguntas relacionadas a temática, tais como: O que você compreende sobre Violência Obstétrica? Quais palavras ou atitudes representa uma Violência Obstétrica? O instrumento foi idealizado num formato de fácil compreensão e de modo que os entrevistadores não induzissem as respostas.

Coletou-se as entrevistas em salas da unidade de saúde e no domicílio do casal, sendo realizadas as entrevistas de forma individual, utilizando-se um gravador de áudio para o registro das informações coletadas. As entrevistas foram transcritas na íntegra, e posteriormente, realizou-se a análise dos dados seguindo as seguintes etapas: a) pré-análise, onde foi realizada a organização e leitura cuidadosa de todo material; b) exploração do material, a partir da leitura horizontal dos dados em seu conjunto, buscando neste processo as aproximações entre as falas; c) análise temática, organizando o texto por aproximação e similaridade em temas principais; d) tratamento das informações, inferência e a interpretação, quando as categorias que foram utilizadas como unidades de análise e foram analisadas à luz da literatura atual (BARDIN L, 2011).

Todos os participantes da pesquisa assinaram o Termo de Consentimento Livre e Esclarecido, sendo assegurados os preceitos éticos. Os mesmos foram identificados nas entrevistas pela letra (C) de casal e um número sequencial, conforme a ordem dos casais entrevistados, respeitando o anonimato dos mesmos. 0 estudo respeitou os preceitos éticos de pesquisa com seres humanos de acordo com a Resolução ํㅜ 510/2016 do Conselho Nacional de Saúde (BRASIL, 2015), e foi aprovado pelo Comitê de Ética em Pesquisa do Centro Universitário Tabosa de Almeida ASCES-UNITA, obtendo parecer favorável ํㅜ 2.874.064, sob nํㅡ CAAE: 96440418.8.0000.5203.

\section{RESULTADOS}

Na caracterização dos participantes, $81 \%$ dos entrevistados compuseram a faixa etária de 20 a 29 anos e a faixa etária de 30 a 39 anos representou $19 \%$ do total de participantes. Percebeu-se quanto ao nível de escolaridade, que $50 \%$ possuíam ensino médio completo e $25 \%$ com ensino superior incompleto (Tabela 1 ).

Tabela 1 - Caracterização sociodemográfica dos participantes.

\begin{tabular}{ccc}
\hline Características & $\mathbf{n}$ & $\%$ \\
\hline Faixa etária & & 81 \\
\hline 20 à 29 anos & 13 & 19 \\
30 à 39 anos & 3 & \\
\hline Escolaridade & & 25 \\
Ensino superior incompleto & 4 & 50 \\
Ensino médio completo & 8 & 25 \\
Não alfabetizado & 4 &
\end{tabular}

Fonte: Borba AM, et al., 2020. 
Observou-se, ainda, que $81 \%$ das gestantes vivenciavam a gestação pela primeira vez e 19\% já haviam experienciado gestação anterior. Já em relação aos companheiros, $81 \%$ também vivenciavam a paternidade pela primeira vez, e apenas $19 \%$ deles possuíram experiência anterior com a companheira.

Ao serem questionados se já ouviram falar sobre o termo violência obstétrica, 4 casais responderam que já ouviram falar sobre o termo, e outros 4 casais afirmaram desconhecer e, após realizar novamente a pergunta "o que eles compreendiam sobre violência obstétrica? ", três casais conseguiram responder e um casal não compreendia nada e desconhecia totalmente o tema.

Construiu-se a partir da análise dos dados, as seguintes categorias temáticas: "Reconhecendo a violência obstétrica apenas no momento do parto"; "Desconhecimento da violência obstétrica"; "Importância da informação acerca da violência obstétrica"; e "A violência obstétrica interferindo na humanização e direitos da gestante".

\section{Reconhecendo a violência obstétrica apenas no momento do parto}

Os casais consideraram a violência obstétrica como o mal atendimento dos profissionais de saúde durante o parto, não sendo citados momentos de pré-natal e puerpério. Destacam-se a ausência de vínculo e comunicação entre a equipe e o casal, a falta de acolhimento, agressões sejam elas verbais, psicológicas ou físicas.

[...] se você continuar a reclamar eu vou deixar você passar mais tempo ainda aí na maca [...]. Na hora de fazer foi bom, mas na hora de ter, aí fica reclamando. Às vezes manda calar a boca. (C1)

Me deixaram lá, numa sala e não foi assim, tipo, o que eu eu esperava de atender bem, porque atendia, de cara feia, tipo falando alto, gritando. (C2)

A privação dos direitos, como também ofensas, acabam coagindo e deixando as parturientes com medo de expressar suas vontades, ou de fazer questionamentos sobre determinados procedimentos.

Não deixa que a gestante interfira de alguma forma com a opinião dela. Vai ser qualquer ato, do profissional da equipe com a gestante, não só com ela, mas com a família, que seja prejudicial a ela fora dos direitos dela. (C3)

Desde a violação de um direito que a gestante tem até agressão verbal e palavras que, às vezes, vem a ofender a gestante no momento que ela tá de maior fragilidade [...] Muitas gestantes, às vezes, ficam até com medo de falar alguma coisa, com medo de acontecer alguma coisa, entendesse? Dela ser violentada, por exemplo, com uma medicação com alguma coisa que viesse a apertar ou fazer uma coisa mal, que viesse a machucar mesmo, fisicamente, durante a hora do parto. (C5)

Alguns relatos dos casais ainda deixaram expressas condutas relacionadas à violência física, ocasionando certo tipo de constrangimento e abalo emocional dessas mulheres.

Eu acho que a violência obstétrica pode ser maus tratos no acompanhamento do parto, né? [...] no pré-natal [...]. De repente é um espancamento alguma coisa também assim. (C4)

[...] tratar mal na hora do parto ou então fazer um corte errado [...] eu não sabia qual procedimento que ela ia fazer e no momento que eu não sabia ela: - você não sabe não, que vai fazer o toque e tal? - bem agressiva, né? Na forma de falar. Então, assim, você já chega tensa devido a um problema e já sai de lá, né? Porque eu saí chorando bastante porque ela me deixou um pouco abalada. (C7)

\section{Desconhecimento da expressão violência obstétrica}

O desconhecimento total sobre o tema foi expresso por um casal, sendo um ponto importante a ser discutido, pois a ausência de informação e divulgação sobre a temática os deixaram intimidados, interferindo nas percepções sobre parto e possíveis identificações de violências obstétricas. 
Eu quase nada, né? Porque nunca assim, é como eu disse eu nunca participei de nenhuma palestra, ninguém nunca me mostrou nada. (C6)

\section{Importância da informação acerca da violência obstétrica}

O acesso à informação com a participação ativa do casal na consulta de pré-natal e o desenvolvimento do plano de parto, junto com a equipe, tornam-se uma estratégia importante na educação em saúde, tendo como benefícios para esse casal o empoderamento sobre determinados assuntos, como a violência obstétrica.

Como a gente tá sendo acompanhado pela enfermeira residente no pré-natal, aí ela tava falando com a gente em relação do parto humanizado, se minha esposa tinha dúvida, se tinha interesse de ter o parto humanizado e ela falou que a gente poderia deixar por escrito as vontades da minha esposa, como ela esperava, aí a gente tá nesse processo de montagem do nosso plano de parto, como a gente espera que seja. (C3)

\section{A violência obstétrica interferindo na humanização e direitos da gestante}

Verificou-se que a violência obstétrica também pode ser manifestada na postura dos profissionais, ao se expressarem de forma grosseira ou ao ignorar ou desvalorizar o casal, dessa forma violando o direito da mulher de ser tratada com respeito e dignidade, como pode-se observar nas falas abaixo:

Eles tratam o paciente não como paciente, mas apenas como se eles estivessem ali, só agindo como se fosse uma máquina [...]. (C3)

Às vezes, na hora do parto, vem uma enfermeira, às vezes, tá com muito tempo de plantão lá, de horas seguidas e tal, está com mal humor e, às vezes, trata de uma forma que não é humanizado, entendesse? Mesmo você já sabendo que ali é um momento de maior fragilidade, momento que tá sentindo muita dor, que tá evoluindo pra o parto, as contrações estão aumentando e fica no estresse muito grande, e fica muito sensível, muito sensível e, ao invés de acolher, às vezes, eles tratam de uma forma muito desumanizada, xingando, dizendo que tem que ser, que é desse jeito mesmo que ela aguente que vai ser dessa forma. (C5)

[...] acho que naquela hora foi uma certa violência, né? [...] porque se ela tava com os problemas dela, a doutora, eu não tinha culpa, e ela, assim, tratou muito mal [...]. (C7)

[...] em relação ao momento do parto quando, os médicos não atendem corretamente e acham que é [...] tem que ser do jeito deles e a mulher, se sentir dor, não é dor para eles [...]. (C8)

A forma como os profissionais prestam atendimento ao casal no momento do parto, com abordagem sem acolhimento, humanização e até mesmo com privação de seus direitos, passa a ser entendido, pelos casais, que esses profissionais não conseguem corresponder às expectativas da humanização do cuidado.

\section{DISCUSSÃO}

A Violência Obstétrica é fenômeno que pode ocorrer durante todo o período de cuidado obstétrico da mulher, havendo uma necessidade de discussões acerca de prevenção quaternária, ou seja, ações individuais, familiares e comunitárias realizadas na unidade de atenção primária à saúde e relacionadas ao pré-natal, bem como ações políticas, sociais e institucionais (TESSER C, et al., 2015).

Existe, ainda, uma necessidade de abordar, de forma aprofundada, a temática "Violência Obstétrica" para o casal grávido, diante da falta de reconhecimento enquanto um ato violento, já que no momento em que ocorrem, as mulheres vivenciam grandes emoções, fazendo-as pensar que é comum experienciar certas abordagens, serem impedidas de exprimir o que sentem durante 0 trabalho de parto, de terem um acompanhante, dentre outras ocorrências, já que o processo de ter um filho denota inúmeros sentimentos inéditos e muitas vezes incompreendidos (ANDRADE BP e AGGIO CM, 2014). 
Boa parte das parturientes não sabe identificar se foram alvos ou não de violência obstétrica, pelo fato de depositarem confiança na equipe que prestam assistência no momento do parto, e pela condição frágil mentalmente e fisicamente que o processo de parto possibilita. É perceptível nesse contexto, a aceitação de intervenções sem questionamentos por parte das mulheres, como também, não expõem suas expectativas, desejos e indagações. Nessa condição, silenciam e desconhecem que foram violentadas OLIVEIRA TR, et al., 2017).

Destaca-se, com isso, que o processo de cuidado é, prioritariamente, de posse da pessoa, a partir do momento que o autocuidado é visto como parte primordial do processo de construção da saúde pública. A pessoa é colocada como centro do cuidado, sendo o profissional a pessoa corresponsável neste processo e auxílio num caminho de saúde baseada em evidências científicas (BARBOSA MS e RIBEIRO MMF, 2016).

No contexto da violência obstétrica, surge a violência de gênero, a qual se enquadra na violência institucional praticada pelas unidades de saúde, que tem como características a negligência e maus-tratos da equipe com a mulher em processo de parto, excluindo-a de seus direitos, a peregrinação por outras instituições em prol de receber atendimento e frases do tipo "na hora de fazer gostou, então não reclama, agora aguenta" são ditas por profissionais, caracterizando-se como um discurso institucional (GOMES AM, 2014).

A violência física, com origens na violência de gênero (PALHARINE LA e FIGUEIRÔA SFM, 2018), está relacionada ao descumprimento de boas práticas, sendo importante para os casais conhecerem que práticas são essas. O descumprimento pode ser encontrado com a utilização de ocitocina de forma incorreta, o exame de toque vaginal, repetitivo, realizado na mesma parturiente por diversos profissionais, a não utilização de métodos de alívio à dor, episiotomias de rotinas e Kristeller, dentre outros procedimentos técnicos sem 0 mínimo de informação para a mulher e sua parceria (GUIMARÃES LB, et al., 2018).

Percebe-se, portanto, que a violência obstétrica de característica física é apontada pelos sentimentos de constrangimento e dor, possibilitando o incômodo no transcorrer da assistência, juntamente com a falta de respeito e invasão da intimidade feminina. (LEAL MC e GAMA SGN, 2014). Nesse mesmo contexto, surge também a violência psicológica, que está atrelada a violência verbal, que se caracteriza pela forma grosseira de se falar, ofensa, intimidação e falta de respeito ao protagonismo que envolve os direitos reprodutivos e sexuais da parturiente, sendo perceptível na realização de técnicas sem o consentimento da paciente (GUIMARÃES LB, et al., 2018).

O impedimento da presença de um acompanhante (Diniz SG, et al., 2015) está incorporado neste processo, e é crucial divulgar a Lei $n^{\circ} 11.108 / 2005$ (BRASIL, 2005) a qual determina que toda mulher tem o direito de ter um acompanhante de sua livre escolha no acolhimento, pré-parto, parto e pós-parto imediato. Isto favorece a construção do novo cenário obstétrico, solicitado pelas próprias mulheres a partir do movimento feminista e movimento de humanização do parto, apoiado pela Organização Mundial de Saúde.

Esse cenário é caracterizado por paulatina desmedicalização da assistência, autonomia, práticas de cuidados baseados em evidências científicas e cuidado em saúde centrado na pessoa, conforme supracitado (BARBOSA MS e RIBEIRO MMF, 2016; PALHARINE LA e FIGUEIRÔA SFM, 2018; ZASCIURINSKI JM, 2015).

Compreendeu-se que todos os tipos de Violência Obstétrica influenciam diretamente na assistência prestada, no vínculo entre o usuário e a equipe e na experiência de parto. Segundo as Diretrizes Nacionais de Assistência ao Parto Normal, as mulheres que vivenciam o processo de parto têm o direito de serem respeitadas, informadas sobre as evidências científicas e serem protagonistas nas suas decisões. Desse modo, é de suma importância a criação de vínculo e confiança com a equipe que a assiste, dispondo de seus desejos e expectativas em relação ao parto, tornando-se conscientes da importância das atitudes dos profissionais, das palavras ditas no momento, seguida de um tom de voz acolhedor e dos cuidados realizados em geral (BRASIL, 2018).

Ressalta-se, ainda, a importância do acesso à informação sobre o plano de parto, que é um documento escrito pela mulher grávida, junto ou não com sua parceria. Após receber informações sobre a gravidez, o 
processo de parto e pós-parto, e considerando seus valores e desejos pessoais, este documento é elaborado com o apoio da equipe de Atenção Primária à Saúde, servindo para orientar o cuidado prestado ao longo de todo o processo (CORTÉS MS, et al., 2015).

Entende-se que a importância do Plano de Parto origina-se no respeito ao Princípio Bioético de Autonomia, estando de acordo com as evidências científicas atuais na saúde, aumentando, assim, o entendimento e controle das mulheres sobre o processo do parto, contribuindo para produzir um efeito positivo no momento da assistência prestada e na preparação para o parto (CORTÉS MS, et al., 2015).

Portanto, a resposta para a violência obstétrica está a rever a assistência prestada às mulheres e suas parcerias, implicando numa nova visão do cuidado por parte dos profissionais da saúde e das pessoas em geral. Isto chama a atenção para a formação acadêmica e permanente dos profissionais de saúde, além da formação popular a partir da educação em saúde na atenção básica (BARBOSA MS e RIBEIRO MMF, 2016). Este processo inclui ressignificação de postura que se assume diante da vida e diante de como você interage com o outro. Portanto, a humanização não custa bilhões e bilhões, nem para o governo, nem para si próprio, compreendendo que o valor da humanização só depende do tamanho da vontade de cada ser (TESSER CD, et al., 2015).

\section{CONCLUSÃO}

A percepção dos casais entrevistados acerca da violência obstétrica permeou o entendimento de práticas ocorridas no momento do parto que venham a constranger o casal, sendo identificadas a violência verbal, psicológica e física, como também a violação dos direitos da gestante. O estudo teve como limitações a não participação do casal durante as consultas de pré-natal e a dificuldade na abordagem do casal, sem interferir em suas atividades diárias. Observa-se, como potencialidade, o despertar para o conhecimento do casal acerca do tema. Desse modo, sinaliza-se para a continuidade das discussões sobre a violência obstétrica como tema que necessita ser discutido, a partir de seu conceito, características, consequências e momentos de ocorrência.

\section{REFERÊNCIAS}

1. ALVARENGA SP e KALI JH. Violência Obstétrica: como o mito "parirás com dor" afeta a mulher brasileira. Rev Univer Vale do Rio Verde, 2016;14(2):641-649.

2. ANDRADE BP e AGGIO CM. Violência obstétrica: a dor que cala. Anais do III Simpósio Gênero e Políticas Públicas, 2014; ISSN 2177-8248

3. BARDIN L. Análise de conteúdo. São Paulo: Edições 70; 2011.

4. BARBOSA MS e RIBEIRO MMF. O método clínico centrado na pessoa na formação médica como ferramenta de promoção de saúde. Minas Gerais, MG, Brasil. Rev Med Minas Gerais, 2016; 26(8):216-222.

5. BRASIL. Ministério Público de Pernambuco. Humanização do parto. Nasce o respeito informações práticas sobre seus direitos, 2015; 19(3):717-24.

6. BRASIL. Ministério da Saúde. Conselho Nacional de Saúde. RESOLUÇÃO № 510, do conselho nacional de saúde de 07 de abril de 2016 (BR). Que trata das especificidades éticas das pesquisas nas ciências humanas e sociais e de outras que se utilizam de metodologias próprias dessas áreas. 2016. Brasília. Disponível em: http://conselho.saude.gov.br/resolucoes/2016/Res0510.pdf.

7. BRASIL. Presidência da República. Lei no 11.108, de 7 de abril de 2005. Altera a Lei n. 8.080, de 19 de setembro de 1990, para garantir às parturientes o direito à presença de acompanhante durante o trabalho de parto, parto e pósparto imediato, no âmbito do Sistema Único de Saúde - SUS. [Internet]. Brasília, DF, Brasil, 2005.

8. BRASIL. Ministério da Saúde. Secretaria de Ciência, Tecnologia e Insumos Estratégicos. Departamento de Gestão e Incorporação de Tecnologias em Saúde. Diretrizes nacionais de assistência ao parto normal. Brasília: Ministério da Saúde, 2017. $51 \mathrm{p}$.

9. CORTÉS MS, et al. Uso e influência dos Planos de Parto e Nascimento no processo de parto humanizado, Ribeirão Preto SP [Internet]. Rev. Latino-Am. Enfermagem, 2015; 23(3):520-6.

10. DINIZ SG, et al. Violência obstétrica como questão para a saúde pública no brasil: origens, definições, tipologia, impactos sobre a saúde materna, e propostas para sua prevenção, São Paulo - SP - Brasil. Journal of Human Growth and Development, 2015; 25(3): 377-376.

11. GOMES AM. Da Violência institucional à rede materna e infantil: Desafios e possibilidades para efetivação dos direitos humanos e redução da mortalidade. Brasília, DF, Brasil. In Cadernos Humaniza SUS, 2014. 
12. GUIMARÃES LB, et al. Violência obstétrica em maternidades públicas do estado do Tocantins, Florianópolis, SC, Brasil. Rev. estud. Feministas, 2018; 26(1).

13. LEAL MC e GAMA SGN. Nascer no Brasil, Rio de Janeiro, RJ, Brasil. Cad. Saúde Pública, 2014; 30(1).

14. OLIVEIRA TR, et al. Percepção das mulheres sobre violência obstétrica, Recife, PE, Brasil. Rev enferm UFPE on line, $2017 ; 11(1): 40-6$.

15. PALHARINE LA e FIGUEIRÔA SFM. Gênero, história e medicalização do parto: a exposição "Mulheres e práticas de saúde". História, Ciências, Saúde - Manguinhos, Rio de Janeiro, 2018; 25(4):1039-1061.

16. SANFELICE CF, et al. Do parto institucionalizado ao parto domiciliar, Fortaleza CE, Brasil. Rev Rene, 2014; 15(2):362-70.

17. TESSER CD, et al. Violência obstétrica e prevenção quaternária: o que é e o que fazer, Rio de Janeiro, RJ, Brasil. Rev Bras Med Fam Comunidade, 2015; 10(35):1-12.

18. ZASCIURINSKI JM. Violência obstétrica: uma contribuição para o debate acerca do empoderamento feminino, 2015. 